\title{
Inhibition of SATB1 expression in regulatory $T$ cells contributes to hepatitis $B$ virus-related chronic liver inflammation
}

\author{
XUE-FEN LI ${ }^{1,2}$, LI TIAN ${ }^{2}$, YI-YIN WANG ${ }^{2}$, HAI-SHEN KONG ${ }^{1}$, YUE-JIAO DONG ${ }^{2}$, \\ QIAO-YUN ZHU ${ }^{2}$, QIN NI ${ }^{1}$ and $\mathrm{YU} \mathrm{CHEN}^{1,2}$ \\ ${ }^{1}$ State Key Laboratory for Diagnosis and Treatment of Infectious Diseases; ${ }^{2}$ Department of Laboratory Medicine, \\ First Affiliated Hospital, School of Medicine, Zhejiang University, Hangzhou, Zhejiang 310003, P.R. China
}

Received November 15, 2013; Accepted May 13, 2014

DOI: $10.3892 / \mathrm{mmr} .2014 .2752$

\begin{abstract}
Regulatory $\mathrm{T}$ cells (Tregs) contribute to the pathogenesis of chronic hepatitis B (CHB). Special AT-rich sequence-binding protein 1 (SATB1) may be a key component of this process. In the present study, Tregs and conventional $\mathrm{T}$ cells (Tconvs) were isolated by magnetic cell sorting of peripheral blood from $\mathrm{CHB}$ patients $(n=57)$, individuals with resolved hepatitis B virus (HBV) infections $(n=15)$, and healthy controls $(n=29)$. SATB1 expression was studied by reverse transcription-quantitative PCR, flow cytometry and immunofluorescence microscopy, and the correlation of SATB1 expression to the expression of liver inflammation serum markers and the $H B V$ DNA load was assessed. CHB patients showed significantly reduced SATB1 expression in Tregs than healthy controls and individuals with resolved HBV infections. Moreover, SATB1 expression in Tregs was significantly lower than in Tconvs of patients with chronic $\mathrm{HBV}$ infection. Serum $H B V$ DNA and liver inflammation markers were inversely correlated to the $S A T B 1$ mRNA level in Tregs. Antiviral treatment was accompanied by increased expression of the SATB1 gene in Tregs. Thus, Tregs from $\mathrm{CHB}$ patients have reduced levels of SATB1, which is resolved with antiviral therapy. Inhibition of SATB1 expression may impair the hepatic inflammatory response and contribute to HBV persistence.
\end{abstract}

\section{Introduction}

Hepatitis $\mathrm{B}$ virus $(\mathrm{HBV})$ remains an important threat to human health worldwide. Moreover, HBV infections have been shown to be the causative agent of the majority of cases of chronic liver disease, liver cirrhosis, and hepatocellular

Correspondence to: Professor Yu Chen, State Key Laboratory for Diagnosis and Treatment of Infectious Diseases, First Affiliated Hospital, School of Medicine, Zhejiang University, 79 Qingchun Road, Hangzhou, Zhejiang 310003, P.R. China

E-mail: zychenyu@126.com

Key words: conventional $\mathrm{T}$ cells, chronic hepatitis B, SATB1, regulatory $\mathrm{T}$ cells carcinoma $(1,2)$. Cellular immune responses play an important role in virus clearance, and impairment of cellular or molecular immune components supports disease persistence and progression. Weak $\mathrm{T}$ cell reactivity to $\mathrm{HBV}$ antigens is believed to be the dominant cause of chronic HBV infection $(3,4)$. However, the mechanisms that are responsible for the impairment of the HBV-specific $\mathrm{T}$ cell response during chronic hepatitis $\mathrm{B}(\mathrm{CHB})$ remain unclear.

Regulatory T cells (Tregs) can suppress HBV-specific cytotoxic T lymphocyte (CTL) proliferation and cytokine secretion (5-8). CHB patients are characterized by an increased percentage of Tregs in the peripheral blood, which has been shown to significantly correlate to the serum viral load $(5,7)$. Based on these findings, it has been hypothesized that Tregs may contribute to an inadequate immune response against the virus, leading to chronic infection. However, much remains to be understood on their antigen specificities and the cellular and molecular pathways involved in their development and mechanisms of action.

Recent studies have identified the special AT-rich sequence-binding protein 1 (SATB1), which is a nuclear matrix attachment DNA-binding transcription factor, as an essential mediator of Treg functionality through its chromatin remodeling activity (9). SATB1 acts as a genome organizer and gene expression regulator $(10-12)$. It has been suggested that the SATB1-mediated inhibition of global chromatin remodeling is necessary for the suppressive activity of Tregs (9).

This study was designed to investigate whether SATB1 contributes to the inadequate immune response that underlies chronic HBV infection. The hypothesis we aimed to test was that $\mathrm{CHB}$ patients show reduced SATB1 expression in peripheral blood $\mathrm{CD} 4^{+} \mathrm{CD} 25^{+}$Tregs compared to healthy individuals, including those with no history of $\mathrm{HBV}$ infection or those who have resolved a previous HBV infection. Our findings showed that SATB1 expression is inhibited in the Tregs of CHB patients but is restored, at least partially, upon antiviral therapy.

\section{Materials and methods}

Study participants. Fifty-seven CHB patients and 15 individuals with resolved $\mathrm{HBV}$ infections were prospectively recruited for this study from the First Affiliated Hospital of the 
Table I. Baseline characteristics of patients and controls.

\begin{tabular}{lccc}
\hline Parameters & $\begin{array}{c}\text { Chronic HBV patients } \\
\mathrm{n}=57\end{array}$ & $\begin{array}{c}\text { Controls } \\
\mathrm{n}=29\end{array}$ & $\begin{array}{c}\text { Resolved HBV patients } \\
\mathrm{n}=15\end{array}$ \\
\hline Age (years) & $32.1 \pm 6.9$ & $29.3 \pm 5.6$ & $35.0 \pm 7.8$ \\
Male $(\%)$ & $42(73.7)$ & $16(55.2)$ & $10(66.7)$ \\
HBV DNA ( $\log _{10}$ copies/ml) & $7.01 \pm 1.81$ & $\mathrm{n} . \mathrm{a}$. & $\mathrm{Neg}$ \\
HBeAg-positive & $38(66.7 \%)$ & $17.9 \pm 2.2$ & $30.8 \pm 4.9$ \\
ALT (IU/l) & $388.3 \pm 68.4$ & $18.3 \pm 0.9$ & $27.5 \pm 3.3$ \\
AST (IU/l) & $199.8 \pm 40.8$ & $12.2 \pm 1.2$ & $15.5 \pm 1.1$ \\
TBiL $(\mu \mathrm{mol} / \mathrm{l})$ & $42.9 \pm 2.2$ & & $\mathrm{~N}$ \\
\hline
\end{tabular}

Data are expressed as mean \pm standard error of the mean or number $(\%)$, unless otherwise indicated. HBeAg, hepatitis B e antigen; ALT, alanine aminotransferase; AST, aspartate aminotransferase; n.a., not applicable; neg, negative; and TBiL, total bilirubin.

Table II. Laboratory test results at baseline and at week 52 of follow-up in 10 patients with CHB.

\begin{tabular}{lccc}
\hline & Baseline & 52 weeks & P-value \\
\hline HBV DNA (log 10 copies/ml) & $7.25 \pm 1.34$ & $2.70 \pm 0.23$ & $7(70)$ \\
HBV-DNA PCR-undetectable (<300 copies/ml) & $0(0)$ & $10(100)$ & 0.001 \\
HBeAg-positive & $10(100)$ & $30.5 \pm 1.9$ & 1 \\
ALT (IU/l) & $201.4 \pm 42.9$ & $10(100)$ & 0.008 \\
ALT (normalized) & $0(0)$ & $0.41 \pm 0.15$ & 0.000 \\
SATB1 mRNA in Tregs (relative expression) & $0.10 \pm 0.09$ & 0.0032 \\
\hline
\end{tabular}

Data are expressed as mean \pm standard error of the mean or number $(\%)$, unless otherwise indicated. Comparisons were performed with $\mathrm{t}$-tests. ALT normalization was defined as serum ALT levels within the normal range (5-50 IU/l). HBV, hepatitis B virus; CHB, chronic hepatitis B; HBeAg, Hepatitis B e antigen; ALT, alanine aminotransferase; SATB1, special AT-rich sequence-binding protein 1; and Tregs, regulatory T cells.

Zhejiang University School of Medicine. CHB diagnosis was performed according to the Chinese consensus criteria (13). Patients were excluded from enrollment if they had previously received antivirus therapy or were currently infected with human immunodeficiency virus or hepatitis A, C, or D virus. A third group of 29 healthy individuals, matched to the HBV groups by age and gender, were recruited as controls. The clinical characteristics of all the study subjects are presented in Table I.

In addition, $10 \mathrm{CHB}$-naive patients were recruited for a longitudinal investigation of the effects of pegylated interferon (Peg-IFN)- $\alpha 2 b$ therapy. Following treatment, patients underwent routine clinical and laboratory (blood) assessments every 12 weeks for one year. The clinical characteristics of the 10 subjects are presented in Table II. All these patients responded to monotherapy, and serum $H B V$ DNA levels were markedly reduced by week 52 of treatment.

All study participants provided written informed consent. The study protocol was pre-approved by the Ethics Review Committee of the First Affiliated Hospital of the Zhejiang University School of Medicine.

Isolation of peripheral blood mononuclear cells (PBMCs) and $C D 4^{+} C D 25^{+} T$ cells. PBMCs were isolated from blood samples $(20 \mathrm{ml}$ each) by Ficoll-Hypaque density gradient centrifugation (Amersham Pharmacia, Uppsala, Sweden), and were snap-frozen or immediately analyzed.

Fresh PBMCs were used for isolation of $\mathrm{CD} 4{ }^{+} \mathrm{CD} 25^{+}$and $\mathrm{CD} 4{ }^{+} \mathrm{CD} 25^{-} \mathrm{T}$ cells. The $\mathrm{CD} 4^{+} \mathrm{T}$ cell population was first obtained by negative selection using a $\mathrm{CD}^{+} \mathrm{T}$ cell isolation kit (Miltenyi Biotec GmbH, Bergisch Gladbach, Germany), and then positive selection was applied with the Midi Magnetic Cell Sorting (MACS) Separator unit (Miltenyi Biotec GmbH) to isolate the $\mathrm{CD} 25^{+} \mathrm{T}$ cell subpopulation. The purity of the subpopulations of $\mathrm{CD} 4^{+} \mathrm{CD} 25^{+}$Tregs and CD $4^{+} \mathrm{CD} 25^{-}$Tconvs was $\geq 90 \%$. Based on previous studies it appears that the positive selection of $\mathrm{CD} 4{ }^{+} \mathrm{CD} 25^{+}$cells did not alter the Treg phenotype (indicative of activity) $(6,14)$.

Flow cytometry. The $\mathrm{CD} 4^{+} \mathrm{CD} 25^{+}$Tregs and the conventional $\mathrm{T}$ cells (Tconvs) $\mathrm{CD} 4^{+} \mathrm{CD} 25^{-}$were simultaneously subjected to immunofluorescent staining to detect SATB1 and FOXP3 expression. Cells were incubated with fluorescein isothiocyanate (FITC)-conjugated anti-human CD4 and peridinin chlorophyll protein (PerCP)-Cy5.5-conjugated anti-human CD25 antibodies at room temperature for $30 \mathrm{~min}$. Following fixation and permeabilization, cells were stained with phycoerythrin (PE)-conjugated anti-human SATB1 antibodies 
A

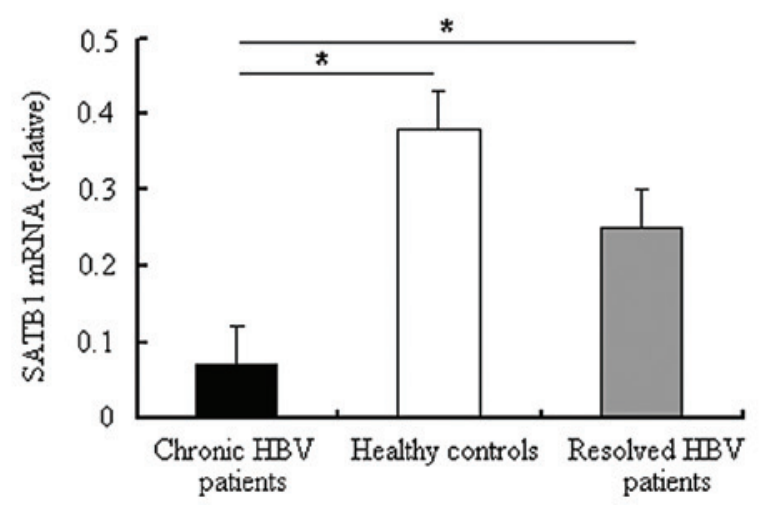

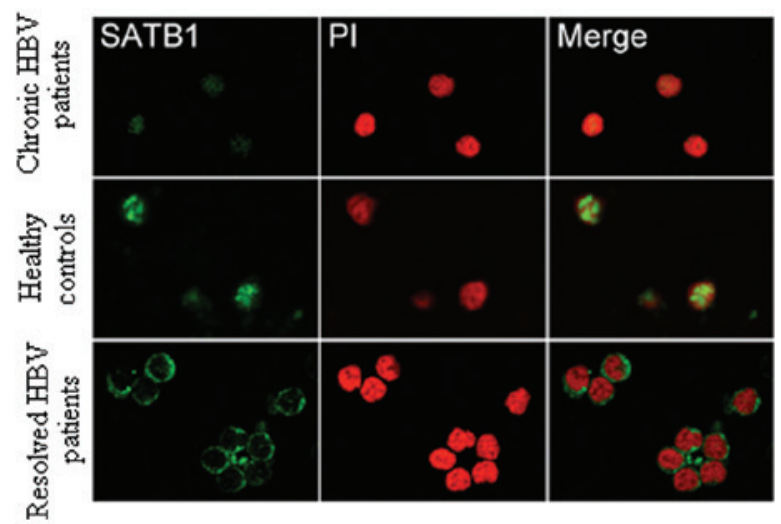

Figure 1. Special AT-rich sequence-binding protein 1 (SATB1) expression in peripheral blood $\mathrm{CD}^{+} \mathrm{CD} 25^{+}$regulatory $\mathrm{T}$ cells (Tregs) of chronic hepatitis B (CHB) patients, healthy controls, and individuals with resolved hepatitis B virus (HBV) infection.(A) Relative mRNA expression determined by reverse transcription quantitative PCR. " $\mathrm{P}<0.05$. (B) Protein expression in single cells determined by confocal microscopy (magnification, $\mathrm{x} 4$ ). PI, propidium iodide.

at room temperature for $30 \mathrm{~min}$. Immunoglobulin (Ig)G1 isotype-matched antibodies served as negative controls. All antibodies were purchased from BD Biosciences (Pharmingen $^{\mathrm{TM}}$; San Jose, CA, USA). Fluorescence intensity data were measured and recorded on a BD FACSCalibur flow cytometer and analyzed by the accompanying CellQuest software (BD Biosciences).

Immunofluorescence staining. The protein expression and cellular localization of SATB1 were determined by immunofluorescence staining. Briefly, the $\mathrm{CD} 4^{+} \mathrm{CD} 25^{+}$Tregs and $\mathrm{CD} 4{ }^{+} \mathrm{CD} 25^{-}$Tconvs were first fixed with cold $4 \%$ formaldehyde for $30 \mathrm{~min}$ at room temperature. After washing with phosphate-buffered saline (PBS), the cells were permeabilized with $0.5 \%$ Triton-X 100 for $15 \mathrm{~min}$ at room temperature and then incubated in $5 \%$ fetal bovine serum for $2 \mathrm{~h}$ at $37^{\circ} \mathrm{C}$ to block non-specific binding sites. Then, overnight incubation was performed at $4^{\circ} \mathrm{C}$ with the primary antibody (purified rabbit anti-human SATB1 antibody or isotype; R\&D Systems, Minneapolis, MN, USA). After two washes with PBS, the Alexa Fluor 488-goat anti-rabbit IgG secondary antibody was added, and the cells were incubated for $60 \mathrm{~min}$ at room temperature. After a final PBS wash, the cells were stained with propidium iodide (PI; BD Biosciences), and fluorescence was examined and recorded using a Leica DMI 4000 microscope equipped with a charge-coupled device camera (Leica Microsystems, Wetzlar, Germany).

RNA isolation, cDNA synthesis, and reverse transcription-quantitative ( $R T-q P C R)$. Total RNA was isolated from MACS-sorted Tconvs and Tregs $\left(2 \times 10^{6}\right.$ cells $/ \mathrm{ml}$ in $\left.100 \mu \mathrm{l}\right)$ with the TRIzol reagent (Invitrogen Life Technologies, Carlsbad, CA, USA), according to the manufacturer's instructions in the reagent kit. Reverse transcription was performed using the ReverTra Ace ${ }^{\circledR}$ qPCR RT kit (Toyobo, Osaka, Japan). The SATB1 mRNA levels were then assessed by qPCR using the Applied Biosystems ${ }^{\circledR}$ Power SYBR ${ }^{\circledR}$ Green PCR Master mix (Thermo Fisher Scientific, Waltham, MA, USA) according to the manufacturer's instructions in the reagent kit. The following TaqMan primers were used for amplification of SATB1: sense, 5'-ATCACCATGGCGACAGGCCG-3' and antisense, 5'-TGGCCGGGTCTTCTGTCGGT-3'. $\beta$-actin was also amplified as the internal control and was used for normalization. The thermal cycling conditions included 40 cycles of amplification with TaqMan probes on an ABI Prism 7900 Sequence Detection system (Thermo Fisher Scientific). Expression was quantified by the comparative cycle threshold $(\mathrm{Ct})$ method.

Serological liver function assessment and HBV DNA detection. The levels of the routine liver function markers alanine aminotransferase (ALT), aspartate aminotransferase (AST) and total bilirubin (TBiL) (normal range: 5-50 IU/1, 8-40 IU/1 and $0-22 \mu \mathrm{mol} / 1$, respectively) were measured using a 7600 Automated Clinical Analyzer (Hitachi Co., Tokyo, Japan).

The serum $H B V$ DNA load of the individuals was quantified using the COBAS Amplicor HBV Monitor assay (Roche Diagnostics, Branchburg, NJ, USA), with a detection limit of 300 viral genome copies $/ \mathrm{ml}$.

Statistical analysis. Statistical analyses were performed with the GraphPad Prism software (GraphPad Software, Inc., La Jolla, CA, USA). Continuous data were expressed as mean \pm standard error of the mean (SEM) and were compared using a Chi-square test, an unpaired t-test or a one-way analysis of variance (ANOVA). Correlation analysis of the detection indicators was performed using the Spearman's nonparametric correlation test. $\mathrm{P}<0.05$ was considered to indicate statistically significant differences.

\section{Results}

Lower SATB1 expression in Tregs of patients with chronic $H B V$ infection. To assess SATB1 expression in Tregs during chronic HBV infection, the mRNA level of SATB1 was quantified with RT-qPCR in Tregs of CHB patients, healthy controls, and individuals with resolved HBV infection (Fig. 1A). Results showed that $\mathrm{CHB}$ patients have a significantly lower $S A T B 1 \mathrm{mRNA}$ level compared to healthy controls $(0.06 \pm 0.02$ vs. $0.38 \pm 0.11, \mathrm{P}=0.011)$ and to individuals who had a resolved HBV infection $(0.06 \pm 0.02$ vs. $0.25 \pm 0.08, \mathrm{P}=0.012$ ); however, the $S A T B 1 \mathrm{mRNA}$ levels were not significantly different between healthy controls and individuals with a resolved $\mathrm{HBV}$ infection. Similar variations in 
A

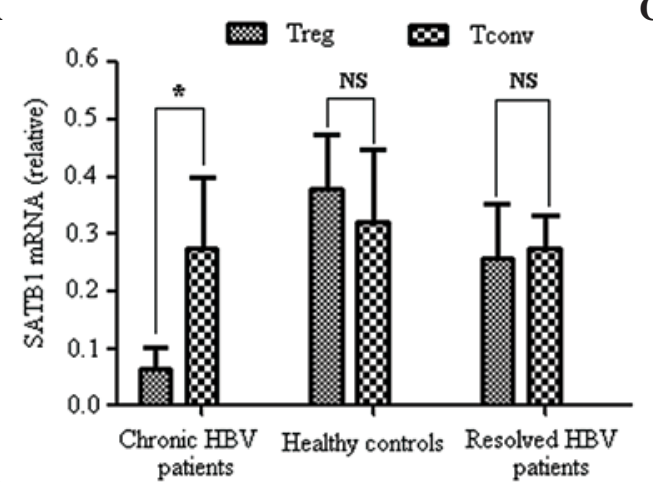

C

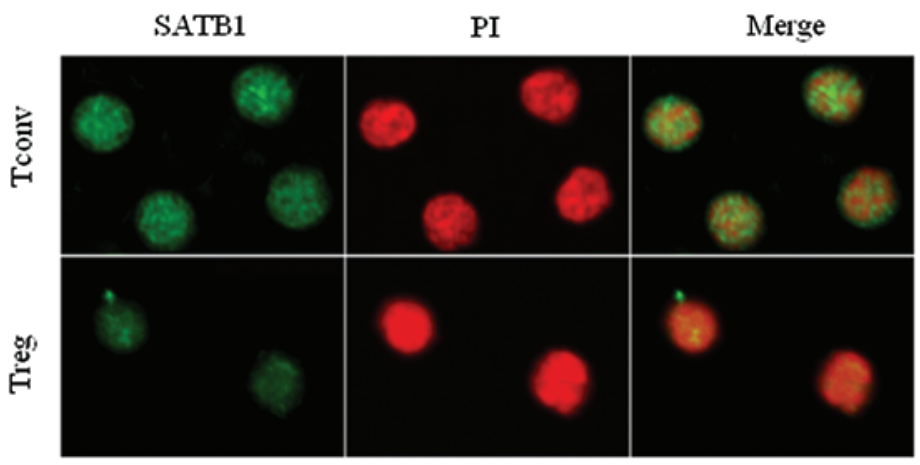

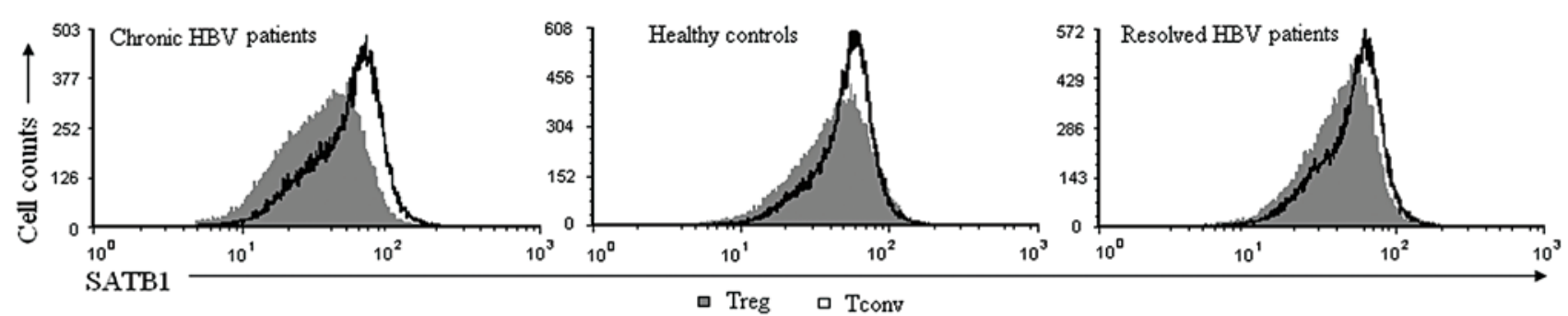

Figure 2. Special AT-rich sequence-binding protein 1 (SATB1) expression in $\mathrm{CD}^{+} \mathrm{CD} 25^{+}$regulatory $\mathrm{T}$ cells $(\mathrm{Tregs})$ and $\mathrm{CD} 4^{+} \mathrm{CD} 25^{-}$conventional T cells (Tconvs) of CHB patients, healthy controls, and individuals with resolved HBV infection. (A) Relative mRNA SATB1 levels determined by reverse transcription-quantitative PCR. "P<0.05 vs. healthy individuals. NS, no significant difference vs. healthy individuals. (B and C) Protein expression determined by (B) flow cytometry and (C) immunofluorescent staining, detected on a confocal microscope (magnification, $\mathrm{x} 4$ ). PI, propidium iodide.

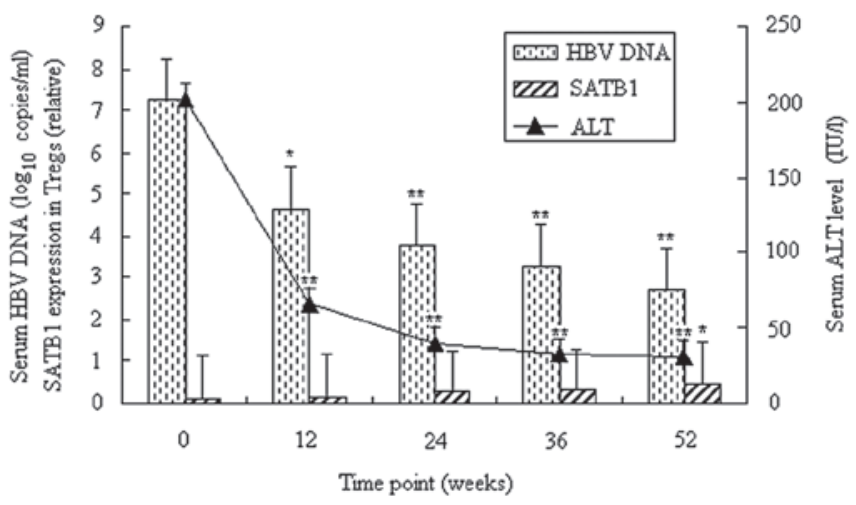

Figure 3. Longitudinal expression of special AT-rich sequence-binding protein 1 (SATB1) in $\mathrm{CD}^{+} \mathrm{CD} 25^{+}$regulatory $\mathrm{T}$ cells (Tregs), serum alanine aminotransferase (ALT) level, and hepatitis B virus ( $H B V$ ) DNA load in chronic hepatitis B (CHB) patients over a 52-week course of pegylated-interferon- $\alpha 2 b$ (Peg-IFN- $\alpha 2 b)$ monotherapy. The average levels of SATB1 mRNA, ALT, and $H B V$ DNA are shown for each time point (baseline and weeks 12, 24, 36, and 52 of monotherapy). Error bars represent standard error of the mean. ${ }^{*} \mathrm{P}<0.05,{ }^{* *} \mathrm{P}<0.01$ vs. baseline.

the SATB1 protein expression were also observed in Tregs from $\mathrm{CHB}$ patients, healthy controls and individuals with resolved $\mathrm{HBV}$ infection (Fig. 1B).

CHB patients show reduced SATBI expression in Tregs compared to Tconvs. To assess the distribution of SATB1 in the different types of $\mathrm{T}$ cells, the mRNA and protein expression of SATB1 was compared between isolated Tregs and Tconvs from CHB patients, healthy controls, and individuals with resolved $\mathrm{HBV}$ infection (Fig. 2A). In $\mathrm{CHB}$ patients, Tregs $\left(\mathrm{CD} 4^{+} \mathrm{CD} 25^{+}\right)$showed significantly lower SATB1 mRNA expression than Tconvs $\left(\mathrm{CD} 4^{+} \mathrm{CD} 25^{-}\right)$ $(0.06 \pm 0.02$ vs. $0.28 \pm 0.09 ; \mathrm{P}=0.019)$. A similar trend was observed when the SATB1 protein expression levels were analyzed (Fig. 2B and C). By contrast, the healthy controls and the individuals with a resolved HBV infection showed no significant differences in SATB1 mRNA expression between Tregs and Tconvs $(0.38 \pm 0.11$ vs. $0.33 \pm 0.16, \mathrm{P}=0.528$; $0.25 \pm 0.08$ vs. $0.27 \pm 0.10, \mathrm{P}=0.839$, respectively) (Fig. $2 \mathrm{~A}$ ).

Effects of Peg-IFN-a2b-suppressed CHB on SATBI $m R N A$ expression in Tregs. To investigate the expression of SATB1 mRNA in Tregs at various phases of antiviral therapy aiming to control chronic HBV infection, $10 \mathrm{CHB}$ patients were studied over a 52-week course of successful monotherapy with Peg-IFN- $\alpha 2 b$. The relative expression of SATB1 gradually and steadily increased in Tregs over the course of antiviral treatment and showed a significant difference between baseline and week 52 (Fig. 3, Table II). The results indicated that $S A T B 1$ expression is increased in Tregs and may play a role in the antiviral-induced suppression of chronic HBV infection.

Correlation of SATB1 mRNA expression to serum biochemical parameters and HBV DNA load. Since CHB patients showed reduced $S A T B 1$ expression in their $\mathrm{CD} 4{ }^{+} \mathrm{CD} 25^{+}$ Tregs compared to healthy controls, we investigated the potential association of SATB1 expression in Tregs with the viral load and liver inflammation markers. A significant negative correlation was observed between $S A T B 1$ mRNA levels in Tregs and the serum levels of the $H B V$ DNA ( $\mathrm{r}=-0.561$, $\mathrm{P}=0.002, \mathrm{n}=33)$, of ALT $(\mathrm{r}=-0.396, \mathrm{P}=0.039, \mathrm{n}=33)$, and of AST (r=-0.519, P=0.043, n=33) (Fig. 4A-C). However, no 
A

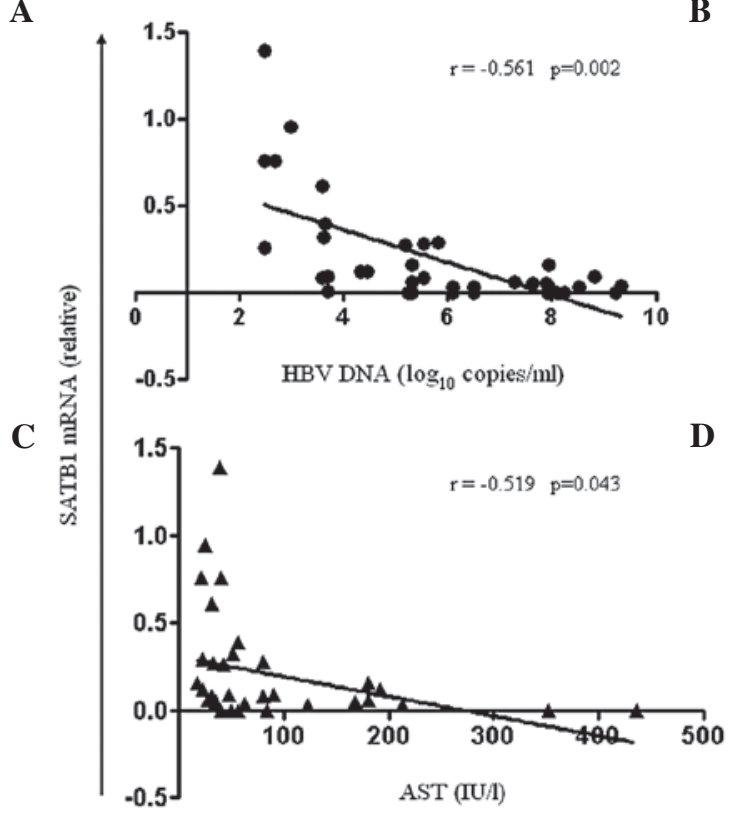

B
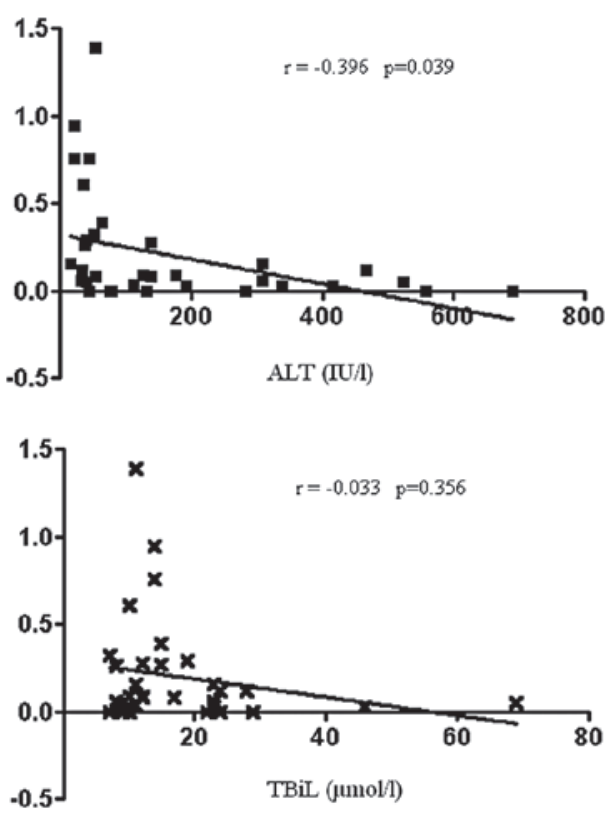

Figure 4. Correlations between (A) $H B V$ DNA levels, serum levels of (B) ALT, (C) AST, (D) TBiL and SATB1 expression in CD4 CD25+ Treg cells of CHB patients $(\mathrm{n}=33)$. ALT, alanine aminotransferase; AST, aspartate aminotransferase; TBiL, total bilirubin; HBV, hepatitis B virus; SATB1, special AT-rich sequence-binding protein 1; Tregs, regulatory T cells; and CHB, chronic hepatitis B.

correlation was observed between SATB1 mRNA expression in Tregs and the serum level of TBiL $(r=-0.033$, $\mathrm{P}=0.356, \mathrm{n}=33$ ) (Fig. 4D).

\section{Discussion}

Tregs play a vital role in the suppression of virus-specific immune responses in chronic viral hepatitis (4-8). CHB patients have a higher percentage of Tregs in the peripheral blood than individuals with no history of HBV infection and those with resolved HBV infection $(5,7)$. Studies on CHB patients have shown that both the circulating and liver-resident Tregs are actively involved in the development of strong HBV-specific cytotoxic T lymphocyte (CTL) responses $(8,15)$. In addition, the mechanisms responsible for the ability of Tregs to suppress the function of other immune effector cells, thereby quelling the immune response, have been elucidated (16). In the present study, we observed that the Tregs of patients with chronic HBV infection express a lower level of SATB1 than those in healthy individuals (either with no history of or with resolved HBV infection). We hypothesize that the reduced SATB1 expression level in Tregs may contribute to the failure of virus-specific $\mathrm{T}$ cell responses in chronically infected patients.

SATB1 was only recently recognized as a critical mediator of $\mathrm{T}$ cell functional plasticity. Specifically, its role in Tconv $\left(\mathrm{CD} 4^{+} \mathrm{CD} 25^{-}\right) / \mathrm{Treg}\left(\mathrm{CD} 4^{+} \mathrm{CD} 25^{+}\right)$conversion can affect the important immunosuppressive function of Tregs (9), impairing systemic clearance of viral pathogens. In the current study, $\mathrm{CHB}$ patients were shown to have a significantly lower level of SATB1 $m R N A$ in their Tregs than in their Tconvs, and this pattern was distinctive from that seen in healthy individuals (with either no history of or resolved HBV infection). Moreover, the SATB1 mRNA levels in the $\mathrm{CD} 4{ }^{+} \mathrm{CD} 25^{+}$Tregs of CHB patients negatively correlated to the expression of hepatic inflammation markers and the $H B V$ DNA load. Additional studies are needed to investigate whether SATB1 expression can act as a marker of the hepatic inflammation status in $\mathrm{CHB}$ patients, or even as a marker of the antiviral treatment response.

SATB1 is a matrix attachment region-binding transcription factor that is expressed predominantly in $\mathrm{T}$ cells and plays crucial roles in $\mathrm{T}$ cell development and activation (10). In fact, inhibition of the expression of SATB1 in Tregs was shown to be required for their immunosuppressive function (9). Previous studies on SATB1 have mainly focused on its roles in thymocyte maturation and on $\mathrm{T}$ and $\mathrm{B}$ cell development $(11,12,17)$. This foundational knowledge has enabled the more recent research interest in the potential correlation of SATB1 with disease pathogenesis; in particular, a number of studies have assessed the role of SATB1 in the development and progression of solid tumors of the breast, stomach, rectum, and liver (18-23). To our knowledge, the research presented herein represents the first clinical study of SATB1 expression related to chronic inflammation of the liver (chronic hepatitis) caused by HBV. The results show that SATB1 may relate to chronic HBV infection.

It is well established that Tregs can influence the antiviral immune response and disease progression in $\mathrm{CHB}$ patients. Antiviral treatment is known to induce a rapid drop in $\mathrm{HBV}$ DNA levels, which is accompanied by a marked decrease in the frequency of Tregs and the expression of Treg-derived cytokines $(5,7,24)$. In the current study, the levels of serum $H B V$ DNA were found to negatively correlate to SATB1 mRNA expression in Tregs of $\mathrm{CHB}$ patients. Moreover, a quantitative reduction in viral replication occurred concomitantly withthe increase in SATB1 expression in Tregs during monotherapy. It is possible that SATB1 might affect the fate of differentiating $\mathrm{T}$ cells and may play a role in the Tregmediated modulation of the immune response in chronic 
HBV infection. This study provided novel insights into the role of SATB1 in chronic HBV infection and highlighted the need for future investigations aiming to determine whether SATB1 may represent a target of new therapeutic strategies for the control of viral hepatitis.

In conclusion, patients with chronic HBV infection show reduced expression of SATB1 gene in their peripheral blood Tregs compared to healthy individuals (with either no history of or resolved HBV infection). The reduced expression of SATB1 in Tregs may affect the ability of these cells to modulate immune responses to viral antigens in chronic HBV hepatitis, which could contribute to persistent HBV infection.

\section{Acknowledgements}

This study was supported by grants from the the Zhejiang Provincial Natural Science Foundation of China (no. LY14H030001), the National Natural Science Foundation of China (no. 81171565) and the Major National S\&T Projects For Infectious Diseases (no. 2012ZX10002002-004).

\section{References}

1. Lee WM: Hepatitis B virus infection. N Engl J Med 337: $1733-1745,1997$.

2. Dienstag JL: Hepatitis B virus infection. N Engl J Med 359: 1486-1500, 2008.

3. Maini MK, Boni C, Ogg GS, King AS, Reignat S, Lee CK, Larrubia JR, Webster GJ, McMichael AJ, Ferrari C, Williams R, Vergani D and Bertoletti A: Direct ex vivo analysis of hepatitis B virus-specific $\mathrm{CD}^{+} \mathrm{T}$ cells associated with the control of infection. Gastroenterology 117: 1386-1396, 1999.

4. Wang FS and Zhang Z: Host immunity influences disease progression and antiviral efficacy in humans infected with hepatitis B virus. Expert Rev Gastroenterol Hepatol 3: 499-512, 2009.

5. Xu D, Fu J, Jin L, Zhang H, Zhou C, Zou Z, Zhao JM, Zhang B, Shi M, Ding X, Tang Z, Fu YX and Wang FS: Circulating and liver resident $\mathrm{CD} 4{ }^{+} \mathrm{CD} 25^{+}$regulatory $\mathrm{T}$ cells actively influence the antiviral immune response and disease progression in patients with hepatitis B. J Immunol 177: 739-747, 2006.

6. Tadokoro CE, Shakhar G, Shen S, Ding Y, Lino AC, Maraver A, Lafaille JJ and Dustin ML: Regulatory T cells inhibit stable contacts between $\mathrm{CD} 4^{+} \mathrm{T}$ cells and dendritic cells in vivo. J Exp Med 203: 505-511, 2006

7. Stoop JN, van der Molen RG, Baan CC, van der Laan LJ, Kuipers EJ, Kusters JG and Janssen HL: Regulatory T cells contribute to the impaired immune response in patients with chronic hepatitis B virus infection. Hepatology 41: 771-778, 2005.

8. Li X, Chen Y, Ma Z, Ye B, Wu W and Li L: Effect of regulatory $\mathrm{T}$ cells and adherent cells on the expansion of $\mathrm{HBcAg}$-specific $\mathrm{CD} 8^{+} \mathrm{T}$ cells in patients with chronic hepatitis $\mathrm{B}$ virus infection. Cell Immunol 264: 42-46, 2010.
9. Beyer M, Thabet Y, Müller RU, Sadlon T, Classen S, Lahl K, Basu S, Zhou X, Bailey-Bucktrout SL, Krebs W, et al: Repression of the genome organizer SATB1 in regulatory T cells is required for suppressive function and inhibition of effector differentiation. Nat Immunol 12: 898-907, 2011.

10. Burute M, Gottimukkala K and Galande S: Chromatin organizer SATB1 is an important determinant of T-cell differentiation. Immunol Cell Biol 90: 852-859, 2012.

11. Nie H, Maika SD, Tucker PW and Gottlieb PD: A role for SATB1, a nuclear matrix association region-binding protein, in the development of CD8SP thymocytes and peripheral T lymphocytes. J Immunol 174: 4745-4752, 2005.

12. Yamaguchi H, Tateno M and Yamasaki K: Solution structure and DNA-binding mode of the matrix attachment region-binding domain of the transcription factor SATB1 that regulates the T-cell maturation. J Biol Chem 281: 5319-5327, 2006.

13. Chinese Society of Hepatology, Chinese Medical Association; Chinese Society of Infectious Diseases, Chinese Medical Association: Guideline on prevention and treatment of chronic hepatitis B in China (2005). Chin Med J (Engl) 120: 2159-2173, 2007.

14. Szodoray P, Papp G, Horvath IF, Barath S, Sipka S, Nakken B and Zeher M: Cells with regulatory function of the innate and adaptive immune system in primary Sjögren's syndrome. Clin Exp Immunol 157: 343-349, 2009.

15. Franzese O, Kennedy PT, Gehring AJ, Gotto J, Williams R, Maini MK and Bertoletti A: Modulation of the CD8+-T-cell response by $\mathrm{CD} 4{ }^{+} \mathrm{CD} 25^{+}$regulatory $\mathrm{T}$ cells in patients with hepatitis B virus infection. J Virol 79: 3322-3328, 2005.

16. Sakaguchi S, Yamaguchi T, Nomura T and Ono M: Regulatory T cells and immune tolerance. Cell 133: 775-787, 2008.

17. Galande S, Dickinson LA, Mian IS, Sikorska M and Kohwi-Shigematsu T: SATB1 cleavage by caspase 6 disrupts PDZ domain-mediated dimerization, causing detachment from chromatin early in T-cell apoptosis. Mol Cell Biol 21: 5591-5604, 2001.

18. Han HJ, Russo J, Kohwi Y and Kohwi-Shigematsu T: SATB1 reprogrammes gene expression to promote breast tumour growth and metastasis. Nature 452: 187-193, 2008.

19. Patani N, Jiang W, Mansel R, Newbold R and Mokbel K: The mRNA expression of SATB1 and SATB2 in human breast cancer. Cancer Cell Int 9: 18, 2009.

20. Cheng C, Lu X, Wang G, Zheng L, Shu X, Zhu S, Liu K, Wu K and Tong Q: Expression of SATB1 and heparanase in gastric cancer and its relationship to clinicopathologic features. APMIS 118: 855-863, 2010

21. Lu X, Cheng C, Zhu S, Yang Y, Zheng L, Wang G, Shu X, Wu K, Liu K and Tong Q: SATB1 is an independent prognostic marker for gastric cancer in a Chinese population. Oncol Rep 24: 981-987, 2010.

22. Meng WJ, Yan H, Zhou B, Zhang W, Kong XH, Wang R, Zhan L, Li Y, Zhou ZG and Sun XF: Correlation of SATB1 overexpression with the progression of human rectal cancer. Int J Colorectal Dis 27: 143-150, 2012.

23. Tu W, Luo M, Wang Z, Yan W, Xia Y, Deng H, He J, Han P and Tian D: Upregulation of SATB1 promotes tumor growth and metastasis in liver cancer. Liver Int 32: 1064-1078, 2012.

24. Zheng Y, Huang Z, Chen X, Tian Y, Tang J, Zhang Y, Zhang X, Zhou J, Mao Q, Ni B, Wang Q and Wu Y: Effects of telbivudine treatment on the circulating $\mathrm{CD}^{+}{ }^{+} \mathrm{T}$-cell subpopulations in chronic hepatitis B patients. Mediators Inflamm 2012: 789859, 2012. 